HASANUDDIN

JOURNAL OF SOCIOLOGY

[HIS]

Volume1, Issue1, 2019

\title{
Identitas Bissu ditengah Modernitas di Desa Bontomatene Kecamatan Segeri Kabupaten Pangkep
}

\author{
(Bissu Identity In The Middle Of Modernity Acase Study In Bontomatene Village Segeri \\ Distric, Pangkep Regency)
}

\section{Syaifullah', Ramli AT ${ }^{2}$, Sawedi Muhammad ${ }^{3}$}
${ }^{l}$ Mahasiswa Magister Sosiologi Fisip Universitas Hasanuddin, Makassar, Indonesia, Email: ifulkasim@gmail.com

${ }^{2}$ Dosen Departemen Sosiologi, Fakultas Ilmu Sosial dan Ilmu Politik Universitas Hasanuddin, Makassar, Indonesia, Email: ramlihat@gmail.com

${ }^{3}$ Dosen Departemen Sosiologi, Fakultas Ilmu Sosial dan Ilmu Politik Universitas Hasanuddin, Makassar, Indonesia, Email: msawedi@yahoo.com

\section{A R T I C L E I N F O \\ How to Cite: \\ Syaifullah, AT, R., \& \\ Muhammad, S. (2020). \\ Identitas Bissu ditengah \\ Modernitas di Desa \\ Bontomatene Kecamatan \\ Segeri Kabupaten Pangkep. \\ Hasanuddin Journal of \\ Sociology (HJS), 3(1), 29-33 \\ Keywords: \\ Role of bissu, culture, bissu identity \\ Kata Kunci : \\ Peran bissu, kebudayaan, identitas bissu

\section{A B S T R A C T}

This study aims to (1) explain the role of bissu in the midst of modernity, (2) factors that cause changes in the role of bissu, (3) and the strategies adopted by bissu in maintaining its cultural existence. This research was conducted in Bontomatenne Village, Segeri Subdistrict, Pangkep Regency. The method used in this research is descriptive and qualitative by interviewing one bissu as the main informant. Data collection is done through observation, interviews and documentation. Data were analyzed by analysis of case studies.The results of this study indicate that public perceptions about bissu, government support, and economic pressure are factors that change bissu's identity and role. The current bissu condition shows a central role in the community in traditional ceremonies and rituals, especially the reception entering the beginning of the harvest season by farmers called the mappalili ritual. However, the role of bissu has diminished due to the community's perception of the existence of a shirk in the bissu culture. The strategy carried out by bissu in maintaining its existence in carrying out its role as a bissu by continuing to carry out traditional ceremonies, maintenance of heirlooms, utilizing social networks and maintaining assets.

\section{ABSTRAK}

Penelitian ini bertujuan menjelaskan peran bissu ditengah modernitas, 
faktor yang menyebabkan perubahan peran bissu, dan strategi yang diadopsi para bissu dalam mempertahankan eksistensi kulturalnya.

Penelitian ini dilaksanakan di Desa Bontomatenne Kecamatan Segeri, Kabupaten Pangkep. Metode yang digunakan dalam penelitian adalah kulitatif yang bersifat deskritif dengan mewawancarai satu bissu sebagai informan utama. Pengumpulan data dilakukan melalui observasi, wawancara dan dokumentasi. Data dianalisis dengan analisis studi kasus. Hasil penelitian ini menunjukkan bahwa persepsi masyarakat tentang bissu, dukungan pemerintah, dan tekanan ekonomi menjadi faktor perubahan identitas dan peran bissu. Kondisi bissu saat ini menunjukkan peran sentral ditengah masyarakat dalam upacara adat dan ritual terutama penyambutan memasuki awal musim panen oleh para petani yang disebut dengan ritual mappalili. Namun peran bissu semakin berkurang disebabkan persepsi masyarakat tentang adanya unsur kesyirikan dalam kebudayaan bissu tersebut. Strategi yang dilakukan bissu dalam mempertahankan eksistensinya dalam menjalankan peran sebagai seorang bissu dengan terus menjalankan upacara adat, pemeliharaan benda pusaka, memanfaatkan jaringan sosial dan mempertahankan aset.

\section{PENDAHULUAN}

E. B. Tylor, Sorokin (1937) sepakat dengan ungkapan kultur atau peradaban adalah satu keseluruhan yang kompleks termasuk di dalamnya pengetahuan, kepercayaan, kesenian, moral, hukum, adat, tradisi, dan segala kemampuan dan kebiasaan lain yang diperoleh manusia sebagai anggota masyarakat. Kultur dipandang mempunyai sifat logico-meaningful integration, semacam integrasi yang dapat dijumpai dalam kesatuan gaya makna dan nilai sebagai karakter struktur sosial, sehingga setiap bagian akan bergantung pada bagian- bagian lain. Budaya atau kebudayaan berasal dari bahasa Sansekerta yaitu buddahayah, yang merupakan bentuk jamak dari buddhi (budi atau akal) diartikan sebagai hal-hal yang berkaitan dengan budi atau akal manusia.

Dari perspektif demikian, muncul anggapan bahwa kebudayaan merupakan keunggulan nilai yang berbaur pada kesepakatan sikap dan keyakinan masyarakat umum, dan bersama-sama dijunjung tinggi oleh mereka yang menganutnya. Pola budaya yang diterapkan memungkinkan untuk menjadikannya sebagai tolak ukur dinamika internal masyarakat itu sendiri. Masyarakat pelaku budaya seringkali dianggap sebagai masyarakat tradisional. Studi masyarakat, jelas tidak dapat dihindarkan dari kedudukan khazanah budaya yang melingkupinya. Gambaran tentang kebudayaan pun tidak mungkin dipisahkan dari retorika sejarah dan politik, yang didukung oleh pembuktian kritis untuk mendapatkan kepastian historisitas (Abdullah,1986)

Menurut kepercayaan masyarakat Bugis, Bissu hadir bersamaan dengan kelahiran suku Bugis. 
Dalam kitab I La Galigo disebutkan bahwa, keberadaan Bissu berkaitan dengan cerita legenda tentang Batara Guru yang menjadi cikal bakal manusia Bugis turun dari “dunia atas” (botinglangi) ke bumi atau dunia bawah (bori'liung) untuk menemui istrinya We Nyili Timo. Ketika Batara Guru turun ke bumi, ia disertai seorang Bissu yang bernama Lae-lae. Bissu ini membantu Batara Guru untuk mengatur kehidupan di bumi. Berkat bantuan Bissu, di bumi tercipta aturan, norma dan etika masyarakat. Selain itu juga tercipta bahasa dan karya-karya budaya dan tradisi sebagai hasil kegiatan masyarakat (Kern, 1993). Sejak beberapa ribu tahun lalu, suku bugis yang mendiami kawasan Sulawesi Selatan. Bissu adalah sebutan bagi pemimpin ritual dari agama bugis kuno, sebelum agama islam masuk dan dianut oleh masyarakat. Kata Bissu, berasal dari kata bessi atau dalam bahasa bugis memiliki arti bersih dan ada pula bissu yang menyatakan bahwa bissu berasal dari kata Bhiksu atau Pendeta Budha (Pelras, 2006)

Masa kerajaan pra Islam di tanah Bugis adalah masa kejayaan para bissu yang dibuktikan dengan peranan yang begitu sentral di kerajaan, sehingga tidak ada kegiatan upacara adat atau ritual kerajaan tanpa kehadiran bissu sebagai pelaksana sekaligus pemimpin prosesi upacara. Setiap ranreng atau setingkat wilayah adat memiliki bissu. Pada setiap upacara adat yang dilaksanakan maka hadir empat puluh bissu yang disebut bissu patappuloe (Farid, 2008). Bissu merupakan potret kebudayaan yang tidak lepas dari kondisi sosial dan geografis Indonesia, hal ini menjadi faktor pendukung bagi masyarakat dalam mengekspresikan kemudian menghasilkan suatu budaya karena kebudayaan merupakan jiwa dan tolak ukur kualitas manusia, kebudayaan adalah milik manusia, hanya manusialah yang berbudaya sebagai wujud dari proses kreatifitas dan produktifitas dalam merambah dan mengemban amanah kekhalifaan dimuka bumi (Farid, 2008).

Runtuhnya Kerajaan Bone di tanah Sulawesi pada masa pemerintahan La Pawawoi Karaeng Sigeri (1895 - 1905 M), berakibat buruk bagi kehidupan kaum bissu. Kehidupan mereka didalam istana kerajaan terpaksa ditinggalkan dan kembali hidup berbaur di tengah masyarakat. Dalam kehidupan kesehariannya, para bissu ini seolah menarik diri. Bahkan mereka cenderung menyembunyikan identitasnya sebagai bissu. Hal ini kemudian memuncak setelah agama islam mulai masuk dan dianut orang Bugis (Trianto, 2003).

\section{METODE PENELITIAN}

Penelitian ini dilaksanakan di Desa Bontomatene Kecamatan Segeri Kabupaten Pangkep Jenis Penelitian ini menggunakan metode kualitatif. Populasi adalah komunitas Bissu yang berada di Bontomatene Kecamatan Segeri Kabupaten Pangkep. Sampel sebanyak 10 informan narasumber dengan metode disproportionate stratified random sampling. Komunitas Bissu yang berada di 
Bontomatene Kecamatan Segeri Kabupaten Pangkep dipilih sebagai sampel penelitian dikarenakan masyarakat tersebut masih mempertahankan tradisi Bissu.

Metode pengumpulan data yang digunakan dalam penelitian ini adalah dengan melakukan proses wawancara mendalam, pengamatan dan dokumentasi. Jenis penelitian yang digunakan adalah jenis penelitian yang bersifat deskriptif yang bertujuan untuk menggambarkan secara objektif dan apa adanya mengenai masalah pokok utama yang akan diteliti sesuai dengan fakta yang ditemui dilapangan. Untuk mendapatkan data yang lebih akurat, maka penulis menggunakan metode studi kasus, yang bertujuan untuk mendapatkan data dan informasi sebanyak mungkin tentang masalah pokok yang akan di bahas.

Analisis data kualitatif menurut Seiddel, prosesnya berjalan sebagai berikut:

1. Mencatat yang menghasilkan catatan lapangan, dengan hal itu diberi kode agar sumber datanya tetap dapat ditelusuri,

2. Mengumpulkan, memilah-milah, mengklarifikasikan, mensintesiskan, membuat ikhtisari, dan membuat indeksnya,

3. Berpikir, dengan jalan membuat agar kategori data itu mempunyai makna, mencari dan menemukan pola dan hubungan-hubungan, dan membuat temuan-temuan umum (Moleong, 2016)

Berdasarkan tahapan analisis data tersebut, maka peneliti menggunakan analisis data dilapangan menggunakan model Miles dan Huberman, proses analisis data yang dilakukan dalam penelitian ini adalah:

1. Reduksi data (Data Reduction), adalah merangkum, memilih hal-hal yang pokok, memfokuskan pada hal hal yang penting, dicari tema dan polanya.

2. Penyajian data (Data Display), dalam penelitian kualitatif, penyajian data dilakukan dalam bentuk uraian singkat dengan teks yang bersifat naratif, bagan, hubungan antar kategori, grafik, matrik, flowchart, dan sejenisnya. Dengan mendisplay data, maka akan memudahkan untuk memahami apa yang terjadi, merencanakan kerja selanjutnya berdasarkan apa yang telah dipahami tersebut.

3. Kesimpulan (Conclusion/ Verification), keismpulan dalam hal ini adalah menjawab dari rumusan masalah yang dirumuskan sejak awal. Kesimpulan data dalam penelitian kualitatif adalah merupakan temuan baru yang sebelumnya belum pernah ada. Temuan dapat berupa deskripsi atau gambaran suatu objek yang sebelumnya masih remang-remang atau gelap 
sehingga setelah diteliti menjadi jelas, dapat berupa hubungan kausal atau interaktif, hipotesis atau teori (Sugiyono, 2009).

\section{HASIL PENELITIAN DAN PEMBAHASAN}

\subsection{Identitas Bissu ditengah Modernitas}

Peneliti menganalisis kontes peran Bissu di Desa Bontomatene Konteks peran Bissu kepada situasi dimana bissu masih sangat berperan penting dalam mempengaruhi atau membawa kelestarian budaya di Segeri Pangkep. Penelitian ini memfokuskan sejauh mana identitas Bissu dalam melestarikan budayanya dalam hal ini peran Bissu bertahan ditengah modernitas. Sebagai bissu. Pada masa pra Islam Bissu merupakan golongan yang sangat penting dan sangat diperlukan dalam kehidupan masyarakat Bugis. Di pundak bissu inilah semua upacara keagamaan dibebankan, untuk dilaksanakan demi memuji sang pencipta. Upacara adat keagamaan Mat Temu Taung (upacara syukuran diakhir tahun) merupakan salah satu upacara yang mengedepankan peran bissu. Acara ini harus dipimpin oleh bissu. Upacara tradisional di Sulawesi Selatan ini bermakna mencari keselamatan dan perlindungan dari sang pencipta (Trianto, 2003)

Sejak tahun 1990 sampai sekarang, komunitas bissu masih dapat di jumpai dan kelihatan masih tetap mempertahankan nilai-nilai luhur budayanya. Eksisnya nilai budaya yang diimplementasikan dalam tradisi, baik yang menyangkut aspek normatif maupun praktek ritual, tercermin pada komunitas bissu yang ada di Sulawesi Selatan seperti di daerah Luwu, Segeri, Bone, Wajo, dan Soppeng yang dalam kenyataannya hingga kini masih berpegang teguh pada warisan budaya leluhurnya walaupun jumlah dan kualitasnya pun semakin menyusut dari hari ke hari (Alam Azis, 2000)

Pembahasan pada bagian ini akan memaparkan dua analisis peran Bissu di desa Bontomatene Kecamatan Segeri Pangkep, di wilayah studi penelitian, yaitu peran Mappalili, dan Peran Arajang menjadi salah satu budaya yang melekat pada kehidupan Bissu.

\section{Peran Bissu dalam adat Mappalili}

Peran Bissu yang sangat istimewa tampak dari namanya, yaitu Bissu berasal dari kata "bessi" yang artinya bersih dalam arti yang luas. Ia tidak berdarah, suci, tidak mengalami menstruasi dan tidak menyusui (Ad'ham, 2009). Hasil penelitian dari segi bahasa Mappalili artinya menjaga susuatu yang akan mengganggu atau menghancurkannya. Dalam ritual adat Mappalili ada benda pusaka yang dicuci atau dibersihkan selama setahun sekali, yakni berupa bajak sawah yang digunakan dalam ritual adat Mappalili. Ritual adat ini dilakukan selama sekali dalam setiap tahun, dan perayaan dilakukan di rumah adat Arajang (tempat menyimpan benda benda pusaka) hal ini dimaksudkan untuk menghormati dan 
menghargai para Dewata yang diyakini sebagai benda pusaka tersebut. ritual adat Mappalili memiliki tahapan tahapan yang telah terintegrasi dengan perkembangan modern, antara lain adanya perubahan waktu dalam proses ritual adat Mappalili, dan kurangnya kepedulian masyarakat terhadap ritual adat yang sejak dulu ada. (Wawancara ANR 10 Maret 2019) Sebagaimana diketahui bahwa Mappalili (mapplili) atau komando turun sawah telah menjadi agenda kegiatan atau tradisi rutin masyarakat setiap tahunnya pada setiap memasuki masa tanam atau memasuki musim penghujan, senantiasa memberikan harapan bagi masyarakat, kuhususnya para petani. Selalu dinanti dan senantiasa memberikan harapan baru bagi masyarakat. Sebagai sebuah produk budaya lokal yang memiliki corak atau warna tersendiri yang menggambarkan karakteristik masyarakat di desa Bontomatene Kecamatan Segeri.

Dalam wawancara yang dilakukan oleh informan ANR terdapat berbagai perubahan yang dialami pada acara mappalili salah satunya tradisi ketika hendak mengawali awal musim hujan atau awal petani turun kesawah, maka ritual yang dilakukan adalah arajang berupa bajak sawah dibawah mengelilingi kampung dengan iringan-iringan warga masyarakat bersorak membawa bajak ke itu kesawah untuk dijampi dan dibacakan mantra-mantra, dalam perjangan iring-iringanan itu seseorang akan menyiram air kepada siapapun yang hendak melintas dijalanan. Padahal yang harus disiram adalah bajak yang hendak dibawah oleh beberapa orang tersebut. dan betemu oleh para (Wawancara 10 Maret 2019).

Bissu dalam pelaksanaannya memiliki aturan atau tatacara yang berbeda dengan upacara adat lainnya. Tentu ada alasan mengapa masyarakat di Segeri Kabupaten Pangkep tetap melaksanakan ritual adat Mappalili alasannya yaitu karena mereka masih menganggap tradisi Bissu adalah kepercayaan dari warisan nenek moyang mereka, dan mereka mempertahankan adat istiadat yang sudah ada sejak dulu yang dilakukan oleh para leluhur mereka sebagai bentuk budaya, Salah satu perubahan yang terjadi pada peran Bissu dalam tardisi Mapalili adalah bajak itu telah dianggap keramat dengan menempatkan benda tersebut sebagai sumber kesematan hidup, hal ini tercermin pada kondisi tertentu masayarakat setempat harus membawa sesajian berupa makanan dan buah sebagai syarat keselamatan dan terhindar dari petaka atau musibah, hal ini diungkap oleh informan ANR, bahwa peran bissu terdahulu tidak mengada mensyaratkan masyarakat untuk melakukan sesembahan atau meminta kepada bendatersebut, apalagi mengkramatkan untuk terhindar dari bahaya dan sebagai bentuk upacara khusus menyambut musim panen sebagai bentuk rasa syukur kepada tuhan, bukan menjadikan mappalili dan bajak sawah tersebut sebagai sumber keselamatan, proses ritual adat Mappalili inilah yang dianggap melenceng dengan nilai nilai budaya Bissu terdahulu. 
Biasanya Mappalili dilakukan pada bulan Oktober atau November, ketika musim hujan tiba. Mappalili dianggap sebagai salah satu ritual pemujaan kepada Dewata. Ritual ini juga sebagai tanda penghormatan dan terima kasih masyarakat atas arajang yang diturunkan oleh Dewata ke muka bumi.

\section{Peran Arajang dan Manggiri}

Dalam pengamatan peneliti melihat bahwa arajang merupakan alasan utama Bissu tetap eksis dalam menjalankan rutual budayanya, dari wawancara yang dilakukan Arajang yang disimpan dalam rumah adat atau yang disebut bola Arajang akan terus dijaga selama Bissu masih ada di tana Segeri. Upacara adat seperti “mattedu Arajang” (membangunkan pusaka yang dikeramatkan).Upacara-upacara ritual Manusia Bissu ini masih dilaksanakan sampai sekarang walau terdapat beberapa perubahan mengingat kondisi sekarang ini tidak sama lagi dengan kondisi sewaktu zaman kerajaan Bugis kuno.

Masyarakat Segeri yang beragama islam menerimah Bissu sebagai sebuah kekayaan budaya dan memiliki nilai nilai luhur dalam menghargai alam semesta, namun tidak untuk menduakan apalagi mengarah kepada kemusyrikan. Manusia Bissu sekarang ini yang notabene para Bissu sendiri pada umumnya beragama Islam. Dengan asumsi ritual itu tidak kekal (dapat berubahubah), maka perubahan ataupun perkembangan ritualisme Manusia Bissu sekarang ini tentunya harus juga ditinjau dari segi perspektif hukum Islam. Peneliti tentunya tetap memfokuskan menganalisis perubahan Peran arajang dalam kebudayaan Bissu.

Arajang (pusaka) berfungsi sebagai simbol adanya kekuatan gaib dengan kelompok atau keluarga tertentu. Dalam sebuah Komunitas Bissu, hubungan itu melalui Puang Matoa. Manusia bissu ini meyakini, jika benda-benda keramat yang terdapat dalam Arajang maka pemilik benda akan senantiasa dibimbing makhluk-makhluk gaib di dalamnya. Namun jika tidak dipelihara, makhluk gaib tidak akan menghiraukan mereka juga, bahkan konon pusaka itu akan hilang misterius (M. Farid W. Makkulau, 2007)

Menurut Puang Matoa PNN dalam wawancara yang dilakukan peneliti, tiap manusia bissu memiliki Arajang, biasanya berupa keris, batubatu, biji buah yang telah kering dan lain sebagainya. Namun tiap Arajang yang dimiliki manusia bissu tentunya harus sejalan dengan nilai-nilai adat suku Bugis. Pada umumnya kekuatan Arajang dapat menyembuhkan orang-orang yang sakit baik secara fisik maupun secara psikologis. Kelebihan yang satu ini merupakan kekuatan Arajang yang pada umumnya orang percaya karena memang beberapa kali terbukti mujarabnya. Memang manusia bissu memiliki Arajang sendiri secara pribadi, namun terdapat juga Arajang secara komunitas yang tentunya memiliki kekuatan yang lebih besar. Arajang yang dimiliki komunitas bissu tersebut berupa bajak tua (rakkala) yang sekarang ini berada di bola Arajang Kecamatan Segeri. Arajang bersama ini langsung dijaga oleh puang matoa. 
Pada masa kerajaan Bugis Kuno, Arajang Bajak Sawah merupakan simbol bagi seluruh masyarakat Bugis yang difungsikan dalam upacara adat Mappalili dan upacara adat mattemu taung. Arajang ini tentunya dijaga oleh manusia bissu yang pada waktu itu jumlahnya sebanyak 40 orang Peneliti menemukan bagian sejarah yang tidak disebutkan dibeberapa buku ilmiah yang membahas tentang manusia bissu, yaitu asal muasal keberadaan Arajang Bajak Sawah di Segeri. Sementara dahulu kala diketahui bahwa Arajang ini berada di Kerajaan Bugis yang letaknya sekarang ini di Kabupaten Bone. Informasi mengenai hal ini memang diketahui manusia bissu pada umumnya karena memang diceritakan sewaktu berguru untuk menjadi manusia bissu. Namun dari tiga manusia Bissu yang peneliti wawancarai, informasi lengkap mengenai asal muasal keberadaan Arajang di Segeri diceritakan langsung oleh Puang Matoa bahkan beberapa manusia bissu sendiri tidak mengetahui secara persis perihal asal muasal Arajang ini di Segeri. (PNN, 10 Maret 2019).

\subsection{Gambaran faktor penyebab perubahan identitas Bissu}

\section{Persepsi masyarakat terhadap Arajang dan Bissu}

Sewaktu peneliti menerapkan teknik snowball sampling sekaligus melakukan observasi, peneliti mendapatkan beberapa isu yang beredar mengenai Arajang Bajak Sawah.Konflik yang terjadi di tubuh komunitas bissu di Kabupaten Pangkep menyebabkan rentangnya isu pelemparan wacana. Isu ini mengenai keberadaan arwah Arajang Bajak Sawah yang sudah tidak lagi berada di Bola Arajang di Segeri,

Permasalahannya adalah isu mengenai hilangnya arwah Arajang Bajak Sawah di Segeri dilontarkan oleh mantan manusia bissu yang menurut informan PNN telah membentuk kelompok sendiri dengan pemusatan ritual di Labakkang Penjelasan informan JU di atas sangatlah penting secara historis mengenai keberadaan Arajang di Segeri. Menurut informan JU, jika roh Arajang Bajak Sawah memang mau menghilang pasti dia akan kembali ke Bone karena keluarga besar Petta Telloe Segeri ada di Kabupaten Bone. Dengan adanya permasalahan-permasalahan yang dihadapi oleh manusia bissu di atas tentu menghambat pelaksanaan ritualisme manusia bissu, yaitu upacara adat Mappalili dan Mattemmu taung. Walaupun demikian, manusia bissu tetap akan berusaha untuk melaksanakan upacara adat Mappalili dan Mattemmu taung. Mengenai bentuk pelaksanaan upacara adat Mappalili dan Mattemmu taung, menurut semua informan tidak ada perubahan dengan pelaksanaan upacara adat sebelumnya.Kalaupun ada, hanya lama pelaksanaannya. Sebagaimana yang diketahui bahwa dulu pelaksanaan upacara adat dilakukan selama empat puluh hari empat puluh malam tapi sekarang Cuma tiga hari tiga malam. (Wawancara SO, 10 Maret 2019) 


\section{Dukungan Pemerintah}

Tidak mudah bagi peneliti untuk mengetahui segala macam problematika Komunitas Bissu. Manusia Bissu sebenarnya cukup tertutup dan sangat berhati hati dalam berbicara apalagi menyangkut keberlangsungan ritualismenya yang merupakan warisan dari nenek moyang dan tentunya senantiasa harus dilestarikan. Salah satu permasalahan yang cukup berpengaruh bagi keberlangsungan ritualisme manusia bissu adalah konflik manusia bissu yang secara langsung dengan dewan adat dan secara langsung dengan dewan pemerintah. Konflik ini dipicu aliran dana dari pemerintah dan bantuan dari berbagai pihak yang dikelola oleh dewan adat Segeri untuk pelaksanaan ritualisme dan kehidupan para manusia bissu.

\section{Faktor Ekonomi (financial capital)}

Dalam pengamatan dan hasil wawancara dengan PNN Kondisi Bissu yang semakin hari jumlahnya, semakin berkurang tidak terlepasdari faktor ekonomi, menjadi seorang Bissu dibutuhkan jaminan penghidupan bagi kelangsungan hidup para Bissu, Berkurangnya jumlah Bissu disebabkan oleh beberapa faktor, baik faktor internal maupun eksternal. Faktor internal adalah menurunnya minat orang untuk menjadi Bissu, karena syarat-syarat yang berat. Faktor ekternal adalah karena perubahan sistim pemerintahan, dari pemerintahan kerajaan menjadi pemerintahan republik. Pada masa kerajaan kehidupan Bissu ditopang oleh kerajaan yang memberikan kemudahan dalam kehidupan ekonomi dan status sosial yang tinggi. Hal ini berubah ketika pemerintahan negara berbentuk republik, yang mengatur pemerintahan daerah dilaksanakan oleh kepala daerah sesuai dengan jenjang hirarkinya dengan masa jabatan yang telah ditentukan. Sejak perubahan status kerajaan menjadi Negara Kesatuan Republik Indonesia, Bissu tidak memiliki sumber ekonomi, karena galung arajang (sawah pusaka) sebagai sumber penghasilan Bissu telah diambil alih oleh masyarakat atau pemerintah daerah.

\section{KESIMPULAN}

Bissu masih tetap mempertahankan eksistensinya ditengah modernitas dalam bentuk ritual Mappalili, salah satu perubahan yang terjadi pada peran Bissu dalam tardisi Mapalili adalah bajak itu telah dianggap keramat dengan menempatkan benda tersebut sebagai sumber kesematan hidup, hal ini tercermin pada kondisi tertentu masayarakat setempat harus membawa sesajian berupa makanan dan buah sebagai syarat keselamatan dan terhindar dari petaka atau musibah, peran bissu terdahulu tidak mengada mensyaratkan masyarakat untuk melakukan sesembahan atau meminta kepada bendatersebut, apalagi mengkramatkan untuk terhindar dari bahaya dan sebagai bentuk upacara khusus menyambut musim panen sebagai bentuk rasa syukur kepada tuhan, bukan menjadikan mappalili dan bajak sawah tersebut sebagai sumber keselamatan, proses ritual adat Mappalili inilah yang dianggap melenceng 
dengan nilai nilai budaya Bissu terdahulu. Selain itu alas an utama Bissu tetap eksis dalam menjalankan ritual budanya karena kebaradaan Arajang (pusaka) yang berfungsi sebagai simbol.

Selain itu faktor penyebab terjadinya perubahan identitas bissu, (1) adaa isu mengenai hilangnya arwah Arajang bajak sawah; (2) konflik manusia bissu yang secara langsung dengan dewan adat dan secara langsung dengan dewan pemerintah; (3) menurunnya minat seseorang menjadi bissu karena syarat-syarat semakin berat; (4) perubahan sistem pemeritahan dari kerajaan menjadi republik.

\section{DAFTAR PUSTAKA}

Ad'ham, S. dan Mabrur, M. 2010. Menjajakan Bissu: Siapa Yang Untung? dalam Agama dan Kebudayaan, Jakarta: Desantara Foundation.

Azis, Nasru Alam. 2005. Yang Tersisa dari Peradaban:Bugis Kuno.(www. boysforum.com, diakses 20 Januari 2008)

Aspryanto. 2007. Kabar Panyingkul: Kisah Seorang Bissu yang Tertusuk Keris Sendiri, (http : //panyingkul. com, diakses 20 Januari 2008

Bourdieu, P. (1984) Distinction: A Social Critique of the Judgement of Taste, Routledge \& Kegan Paul, London.

DR. Gilbert Albert Hamonic, 1986, La Galigo, Menelusuri Jejak Warisan Sastra Dunia, Jakarta : Pustaka Media.

E.B Taylor, 1871, Primitive Culture; ed. Pitirim Sorokin, Social and Cultural Dinamic, 1937, London : Bedminster Press.

Foucault, Michel, 1978. The History of Sexuality, Vol I: An Introduction. New

York, Pantheon Books. Foucault, Michel, 1995. Discipline and Punish; the Birth of the Prison, Vintage Books.

Frosh, S. (1999) 'Identity' in Bullock and Trombley (eds) (1999).

Gobel, Amril Taufik. 2007.Bissu, Celah Tersisih Budaya Bugis. (http ://www. geocities.com, diakses 20 Januari 2008)

Gonggong, Anhar. 2004. Abdul Kahar Muzakkar Dari Patriot Hingga Pemberontak. Yogyakata : Ombak

Graham, Sharyn, 2014. It's Like One Of Those Puzzles: Conceptualising Gender Among Bugis. London. Routledge.

Hamonic, Gilbert Albert. 1986. La Galigo, Menelusuri Jejak Warisan Sastra Dunia, Jakarta : Pustaka Media.

Koentjaraningrat. 1984. Kebudayaan, Mentalitas, dan Pembangunan. Jakarta: Gramedia.

Kartidirjo, Sartono. 1992. Pendekatan Ilmu-Ilmu Sosial dalam Metodologi Sejarah, Jakarta: Gramedia Pustaka Utama.

Koentjaraningrat, 1980. Sejarah Teori Antropologi I. Jakarta UI Press

Lathief, Halilintar. 2004. Bissu : Pergulatan dan Peranannya di Masyarakat Bugis. (www. ham. go.id, diakses 20 Januari 2008)

Mappangara, Suriadi dan Irwan Abbas, 2003 Sejarah Islam Sulawesi Selatan, Makassar Lamacca Press. Mattulada, 1998. Sejarah Masyarakat dan Kebudayaan Sulawesi Selatan, Hasanuddin University Press

Munandar Soeleman, 1992, Ilmu Budaya Dasar, Bandung : PT. Eresco

Mappangara, Suriadi dan Irwan Abbas, 2003 Sejarah Islam Sulawesi Selatan, Makassar Lamacca Press. Mattulada, 1998. Sejarah Masyarakat dan Kebudayaan Sulawesi Selatan, Hasanuddin University 
Press.

Masri, Andi Sulfana. 2015. Kajian Semiotika Dan Nilai-Nilai Memmang Dalam Ritul

Parsons, T. (1951) The Social System, The Free Press, New York.

Parsons, T. and Bales, R. F. (eds) (1955) Family, Socialization and Interaction Process, The Free Press, New York.

Pelras, Christian. 2006. Manusia Bugis. Jakarta: Penerbit Nalar.

Parsons, T. and Bales, R. F. (eds) (1955) Family, Socialization and Interaction Process, The Free Press, New York.

Syahrir, Nurlina. 2003. Bissu dalam masyarakat Pangkep (kedudukan, Upacara, dan Sejarahnya). Makassar : Badan Pengembang Bahasa dan Seni FBS UNM kerjasama Yayasan Adikarya Ikapi dan The Ford Foundation

Sarup, M. (1988) An Introductory Guide to Post-Structuralism and Postmodernism, Harvester Wheatsheaf, Hemel Hemstead.

Saussure, F. (1966) Course in General Linguistics, McGraw-Hill, New York.

Shills, E. (1978) 'Mass Society and its Culture' in Davison et al. (eds) (1978).

Spencer, H. (1971) Structure, Function and Evolution, Nelson, London.

Storey, J. (1997) An Introductory Guide to Cultural Theory and Popular Culture, edn, Harvester Wheatsheaf, Hemel Hemstead.

Strinati, D. (1995) An Introduction to Theories of Popular Culture, Routledge, London.

Suliyati, Titiek. 2018. "Bissu: Keistimewaan Gender dalam Tradisi Bugis”. Jurnal Endgami. Volume 2 no. 1 tahun 2018.

Suliyati, Titiek. 2018. "Bissu: Keistimewaan Gender dalam Tradisi Bugis". Jurnal Endgami. Volume 2 no. 1 tahun 2018

Thompson, E. P. (1963) The Making of the English Working Class, Penguin, Harmondsworth.

Thornton, S. (1997) 'General Introduction' in Gelder and Thornton (eds) (1997).

Weedon, C. (1994) 'Feminism and the Principles of Poststructuralism' in Storey (ed.) (1994). http://www.appadurai.com/homebio.htm

Wunderlich, Jens-Uwe dan Meera Warier. 2007. A Dictionary of Globalization. London: Routledge Hlm.35

http://www.abc.net.au/indonesian/2019-02-27/jumlah-bissu-di-masyarakat-bugis-kianmenyusut/10853024

http://nasrualam.multiply.com/bissu-bugis. 